\title{
Proposal for a Brazilian Centre on Alternative Test Methods
}

\author{
Chantra Eskes ${ }^{1}$, Vanessa de Moura Sá-Rocha ${ }^{2}$, Jadir Nunes ${ }^{3}$, Octavio Presgrave ${ }^{4}$, \\ Dermeval de Carvalho ${ }^{5}$, Philippe Masson ${ }^{6}$, Ekaterina Rivera $^{7}$, Sandra Coecke ${ }^{8}$, Joachim Kreysa ${ }^{8}$ \\ and Thomas Hartung ${ }^{9}$ \\ ${ }^{1}$ Independent Consultant, Ispra, Italy; ${ }^{2}$ Natura, Cajamar, SP, Brazil; ${ }^{3}$ Brazilian Association of Cosmetology, São Paulo, SP, Brazil; \\ ${ }^{4}$ National Institute of Quality Control in Health (INCQS), Oswaldo Cruz Foundation (FIOCRUZ), Rio de Janeiro, RJ, Brazil; \\ ${ }^{5}$ Biotox, Ribeirão Preto, SP, Brazil; ${ }^{6}$ EVIC International, Paris, France; ${ }^{7}$ Biological Science Institute, Federal University of Goiás, \\ Brazil; ${ }^{8}$ ECVAM, In Vitro Methods Unit, Institute for Health and Consumers Protection, European Commission Joint Research \\ Center, Ispra, Italy; ${ }^{9}$ Johns Hopkins University, Baltimore, USA and University of Konstanz, Germany
}

\begin{abstract}
Summary
Several initiatives have recently taken place in Brazil in order to foster the creation of centers dedicated to alternatives to animal testing. In 2008, Vanessa Sá-Rocha organized a meeting with Brazilian regulatory authorities and the major stakeholders in the field of testing to foster discussions on the process of funding, development, and validation of alternative methods in Brazil. Octavio Presgrave published a scientific article on "The Need for the Estabiishment of a Brazilian Centre for the Validation of Alternative Methods." Also in 2008, Jadir Nunes, together with Dermeval de Carvalho, prepared and presented a proposal to the Brazilian National Agency of Health Surveillance (ANVISA) for the creation of a Centre for the Validation of Alternative Methods. ECVAM and other European stakeholders have been involved in the initiatives. Furthermore, also in 2008, a new legislation has been adopted in Brazil regarding the use of animals for scientific purposes ("lei Arouca"). The legislation establishes, among other provisions, the task of monitoring and evaluating the introduction of alternative methods. However, the legislation does not provide for promotion of or information about, existing alternative methods to the larger Brazilian scientific community. In order to streamline the different activities, Chantra Eskes acted as a facilitator by establishing a new joint proposal with the current Brazilian stakeholders, aimed at setting up a Brazilian Center on Alternative Test Methods.
\end{abstract}

Keywords: Brazilian Center, promotion, development, validation, alternative methods

\section{Background}

In 2005, the Instituto Nacional de Controle e Qualidade Sanitária (INCQS) organized EMALT (Encontro sobre Métodos Alternativos ao Uso de Animais para Fins Regulatórios), a meeting on alternative test methods for regulatory use. Some 100 participants took part in presentations and roundtable discussions led by Brazilian and European authorities, along with major national and international stakeholders in the field of toxicological testing. The aim was to initiate discussions on the process of funding, development, and validation of alternative methods in Brazil (Presgrave and Bhogal, 2005). The roundtable discussions involving Octavio Presgrave, Philippe Masson, and Chantra Eskes led to the conclusion that Brazil would ben- efit from having an institution for the validation of alternative test methods to favor the development and define the criteria of acceptance of alternative test methods to be used and/or adapted by the Brazilian regulatory framework.

Since then, few activities took place until last year, when new initiatives were undertaken:

- InAugustof2008, VanessaRochafromNatura, animportantBrazilian cosmetics industry, organized a meeting of Brazilian regulatory authorities and national and international stakeholders in the field of testing to foster discussions on the process of funding, development, and validation of alternative methods in Brazil.

- In November/December of 2008, Jadir Nunes from the Brazilian Association of Cosmetology, together with Dermeval

Received $4^{\text {th }}$ November 2009, accepted for publication $4^{\text {th }}$ December 2009 
de Carvalho, provided a proposal for the creation of a Centre for the Validation of Alternative Methods to the Agência Nacional de Vigilância Sanitária (ANVISA).

- In December of 2008, Octavio Presgrave from the INCQS published a scientific article on "The Need for the Establishment of a Brazilian Centre for the Validation of Alternative Methods" (Presgrave, 2008).

Also in 2008, a new legislation was adopted by Brazil regarding the use of animals for scientific purposes (law n. ${ }^{\circ} 11.794$ or "lei Arouca"). It establishes, among other provisions, the task of monitoring and evaluating the introduction of alternative methods (Brazil, 2008). However, the promotion and information of existing alternative methods to the larger Brazilian scientific community is not foreseen within the legislation.

The present proposal has been drafted to help streamline the different activities and to consider the novel needs related to alternative test methods in Brazil. It represents an initial step that could serve as a basis for discussions and, ultimately, generate consensus on the way to proceed.

\section{Current needs}

Regulatory, commercial, industrial, scientific, ethical, national, and international interests, as described below, would benefit from the creation of a Brazilian center for the promotion of the $3 \mathrm{Rs}$ principles and for the validation of alternatives to animal testing.

\subsection{Regulatory framework}

In 2008 the "lei Arouca" was adopted in Brazil (law n. 11.794 , Brazil, 2008). It established the Conselho Nacional de Controle de Experimentação Animal, or CONCEA, which has, among other duties, the task of monitoring and evaluating the introduction of alternative methods. However, the promotion of, and the provision of information about, existing alternative methods to the larger Brazilian scientific community were not foreseen the legislation.

On the other hand, in the field of toxicological testing and hazard assessment, several alternatives to animal testing have already been adopted internationally within the OECD Test Guidelines program or the Pharmacopeia (e.g., OECD TG 430 to 432 , and more recently OECD TG 437 and 438). For these methods to be accepted at the regulatory level, their relevance and reliability in ensuring consumer safety need to be validated. In 2005, a Guidance Document on the "Validation and International Acceptance of New or Updated Test Methods for Hazard Assessment" was internationally adopted as the OECD GD 34 (2005). It describes, in particular, the internationally agreed principles for the validation of alternative methods to animal testing for the toxicological assessment of chemicals.

Although several countries have established bodies that focus on the promotion and validation of alternative methods to animal testing, Brazil is not yet among them. Indeed, centers for the promotion and validation of alternative methods exist in Europe (ECVAM), in the USA (ICCVAM), and in Japan
(JACVAM), and others are currently being established in other countries, including Korea, China, and India.

Furthermore, an International Cooperation on Alternatives Test Methods (ICATM), was recently established to promote harmonization of standards according to internationally agreed principles, and to favors collaboration for the validation of alternative test methods.

The creation of a Brazilian Centre on Alternative Test Methods and its presence in the national and international arena, such as OECD, Pharmacopeia, and ICATM, represents a requirement to 1) favor harmonization of Brazilian standards in the field of alternative methods to animal testing and, whenever applicable, their accordance to the internationally agreed guidelines and principles; 2) promote Brazilian regulatory and commercial requirements in the field of scientific and toxicological testing; and 3) foster Brazilian communication with international bodies.

\subsection{Commercial and industrial framework}

One of Brazil's most important resources, the vast Amazon bay, holds tremendous promise for the potential discovery and exploitation of novel natural ingredients. Quality and safety testing are required, however, for the commercialization of such novel raw materials (e.g., identifying a specific mode of action or discarding a potential toxicological effect). For that purpose, relevant alternative methods are generally used to reduce the time needed for screening of new ingredients with relation to the traditional animal test, and to decrease the costs linked to a potential failure that could happen at a later stage of development due, for example, to the low mechanistic relevance of the traditional animal tests in relation to the human metabolism. Similarly, during the early phases of development of a new product (e.g., cosmetic, pharmaceutical, or food), valuable alternatives are generally used within industry for screening, efficacy testing, and/or preclinical testing purposes. Here again, the use of relevant alternatives in the early testing phases can reduce both costs ans failure during the later phases of clinical and toxicological studies.

With regard to the international commercial and industrial framework, recent European legislations calls for the use of non-animal testing. The European Cosmetics Directive has established a marketing ban, which came into effect in March 2009 on cosmetic products containing ingredients that would be tested on animals, and, since September 2004, on finished cosmetic products tested on animals. In addition, the European regulation on chemicals ( $\mathrm{REACH})$ requires toxicological information on roughly 30,000 existing chemicals. As a base-testing requirement for raw materials marketed in volumes lower than 10 tons/year, toxicological information coming from non-animal testing is required for 3 out of 5 endpoints.

In order for Brazilian industries to strengthen their international market position and benefit from approximately 500 million European consumers, the promotion and validation of up-to-date alternative methods will be essential to Brazilian industry. The use of alternative methods might also help decreasing time and costs linked to the testing of new ingredients such as those coming from the Amazon bay, and of new products developed by Brazilian industry. 


\subsection{Scientific framework}

Alternative methods ought to be (in some cases) mechanistically more relevant in predicting a human health effect than traditional animal testing. One well-known example is the species differences related to the metabolic competence of liver cells, which result in the generation of different metabolites derived from the parent compound due to differences in metabolism or so-called biotransformation (Coecke et al., 2006). New OECD draft test guidelines acknowledge this difference and begin to incorporate the information derived from in vitro models to allow a more scientifically-based experimental design. Such aspects are essential when dealing with evaluation of systemic toxicities such as reproductive toxicity, repeated-dose toxicity, etc. Metabolism-mediated species differences frequently account for the failure of new pharmaceutical entities in the clinical phases. However, it is generally recognized that if basic research is often carried out using in vitro or ex vivo test methods, very few of these alternatives are designed specifically to predict the effects a substance may have for regulatory purposes (Eskes and Zuang, 2005).

Informing academic scientist about the regulatory needs for alternative methods to animal testing can help in the development of new methods with direct industrial and regulatory applications. This could lead to the development of a new market based on novel in vitro technologies, similar to what is currently occurring in Europe and the USA. Furthermore, it may lead to the development and validation of alternative methods that are more readily accessible and less costly for the Brazilian needs with respect to methods coming from foreign countries.

\subsection{Ethical framework}

It is generally accepted that an experiment should not be performed using an animal if another scientifically satisfactory method of obtaining the result is reasonably and practicably available. For this reason, it is recommended that research into the development and validation is carried out on alternative techniques that provide the same level of information as that obtained in experiments using animals, but which involve fewer animals or entail less painful procedures in order to apply the 3Rs principles on Refinement, Reduction, and Replacement of animal testing. However, very often training and information on the application of the $3 \mathrm{Rs}$ for that purpose are lacking.

The Brazilian Centre on Alternative Test Methods would serve as a focal point of information, discussions, and training for the Brazilian scientific community, with assistance to academia and industry as well as regulators, in order to favor a harmonized and common understanding on the principles of the $3 \mathrm{Rs}$, the validation of alternative test methods, and the various benefits alternative methods can providefor basic research, industrial testing, or regulatory requirements.

\section{Main Activities and Structure}

The intention of the Brazilian Centre on Alternative Test Methods is to bridge the needs of government, industry, academia,

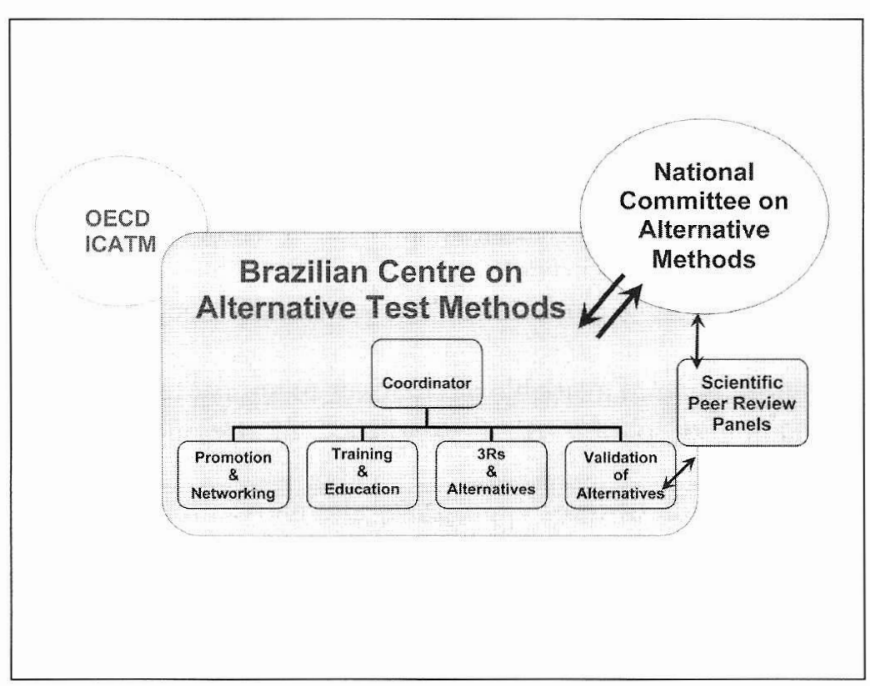

Fig. 1: Proposed structure for the Brazilian Centre on

Alternative Test Methods

NGOs, and international organizations by offering the following services:

1. Promotion of up-to-date information to Brazilian scientists and regulators on alternatives to animal testing (the $3 \mathrm{Rs}$ principles, standards of internationally agreed requirements, and validated and available alternatives to animal testing) through centralized website, database, and publications;

2. Communication and networking of interested parties involved in the $3 \mathrm{Rs}$ and alternatives to animal testing through seminars and workshops;

3. Identification of regulatory, industrial and academic needs of available alternatives;

4. Training and education in the $3 \mathrm{R}$ s principles, on the principles of validation, and on validated alternative methods;

5. Brazilian and international validation of alternative methods.

A proposed structure for the Brazilian Centre on Alternative Test Methods is given in Figure 1. A National Committee on Alternative Methods may act as an advisory committee responsible for identifying the needs and priorities of the center's main activities. In addition, it may interact with the peer review panels for the scientific peer review of validation studies and the Brazilian endorsement of the validity of alternative test methods. Such council may have representatives from regulators and ministries of relevance, industry stakeholders, Brazilian scientific associations of relevance, academia, and animal welfare organizations.

The Brazilian Centre on Alternative Test Methods main activities are proposed to be divided according to the following tasks:

Promotion and Networking

- Creation and maintenance of a centralized website and a centralized database on alternative methods

- Monitoring and creation of a network of interested parties on alternative methods in Brazil 
- Organization of seminars and specialized workshops

- Publications

Training and education

- Training on the uses and applications of the 3Rs principles

- Training on internationally agreed principles of validation

- Practical courses on validated alternative methods

Three $R s$ and alternatives

- Identification of current regulatory, industrial, and academic needs

- Identification of available alternatives to animal testing

- Creation of platforms of excellence in specific fields of expertise

- Identification of most appropriate alternatives for regulatory and non-regulatory applications (e.g., toxicological assessment, efficacy testing, screening purposes, scientific experimentation, and education).

Validation of alternatives (methods) for regulatory purposes

- Coordinating studies on the development of alternative methods to animal testing

- Coordinating validation studies of alternative methods to animal testing

- Proposing and evaluating test protocols

- Participation in international validation studies

- Publication of reports about the progress of studies

\section{Expected outcome}

The creation of a Brazilian Centre on Alternative Test Methods shall be beneficial to achieve several Brazilian and international goals, including:

- Harmonizing the Brazilian standards in the field of alternative methods to animal testing, and their accordance with internationally agreed guidelines and principles.

- Enabling the marketing of novel Brazilian ingredients and products, including the large potential for novel natural ingredients from the Amazon bay, in the European market by complying with the requirements of the EU REACH Regulation and the $7^{\text {th }}$ Amendment to the Cosmetics Directive.

- Promoting, developing, and validating alternative methods to animal testing in Brazil.

- Favoring the development and validation of less costly and more readily accessible alternatives to the Brazilian scientific community.

- Promoting discussions and training on $3 \mathrm{Rs}$ and alternative methods in Brazil.

Overall, the creation of a Brazilian Centre on Alternative Test Methods, as proposed here, would help bridging the Brazilian scintific, commercial, and regulatory needs in the field of alternative test methods. Futhermore, it can help foster the harmonization of Brazilian and international commercial, regulatory, and ethical standards in the field of alternatives.

\section{References}

Brazil (2008). Law n. ${ }^{\circ}$ 11.794, November 08, 2008.

Coecke, S., Ahr, H., Blaauboer, B. J. et al. (2006). Metabolism: A Bottleneck in In Vitro Toxicological Test Development. ECVAM Workshop 54. ATLA 34, 49-84.

Eskes, C. and Zuang, V. (eds.) (2005). Alternative (non-animal) Methods for Cosmetics Testing: Current Status and Future Prospects. A report prepared in the context of the 7th Amendment of the Cosmetics Directive for establishing the timetable for phasing out animal testing. ATLA 33 Suppl. 1, 1-227.

OECD (2005). Guidance Document on the Validation and International Acceptance of New or Updated Test Methods for Hazard Assessment. Environmental Health and Safety Monograph Series on Testing and Assessment No. 34. Available at: http://www.oecd.org/document/30/0,3343,en_2649_34377_1 916638_1_1_1_1,00.html. Accessed on 13.10.2009.

Presgrave, O. A. (2008). The need for the Establishment of a Brazilian Centre for the Validation of Alternative Methods (BraCVAM). ATLA 36, 705-708.

Presgrave, O. A. and Bhogal, N. (2005). EMALT: A Brazilian Meeting on Alternative Methods to Animal Use for Regulatory Purposes. ATLA 33, 670-672.

\section{Correspondence to}

Chantra Eskes, PhD

Via Milano, 34

21027 Ispra (VA)

Italy

e-mail: eskesch@yahoo.com 